\title{
Maravilhosa história
}

A LINHA do tempo do design gráfico no Brasil é um livro ambicioso, uma obra de referência e uma viagem de descoberta e de espanto. Mas está longe de ser perfeito quando consideramos o modo e o tempo em que foi publicado o nosso tempo.

Este livro nasceu da necessidade de um dos seus autores, a designer Elaine Ramos, de acrescentar uma seleção de design brasileiro ao livro História do design gráfico de Phillip B. Meggs e Alston W. Purvis, uma incontornável história universal da disciplina publicada em 2009 pela Cosac Naify, editora da qual ela é diretora de arte. Para a ajudar, chamou o designer e professor Chico Homem de Melo, autor de outras obras dedicadas ao design e à sua história. Três anos depois, o que era para ser um anexo a um livro de 720 páginas tornou-se noutro livro de 744 .

Segundo os seus autores, esta "obra panorâmica" pretende "contribuir para a constituição e consolidação de uma memória do design e da cultura do país". Para tal é dada ênfase à "trajetória da linguagem, não da profissão ou dos profissionais" do design no Brasil, ou seja, em vez de apresentar um friso dos heróis do design brasileiro, esse preocupa-se antes em mostrar o resultado do trabalho da multidão de profissionais, muitos deles anônimos, que projetaram a paisagem visual de uma nação.

$\mathrm{Na}$ sua "crônica do processo de trabalho", os autores explanam de forma exemplar a metodologia com que eficazmente organizaram uma cronologia que começa em 1808 e termina no dealbar

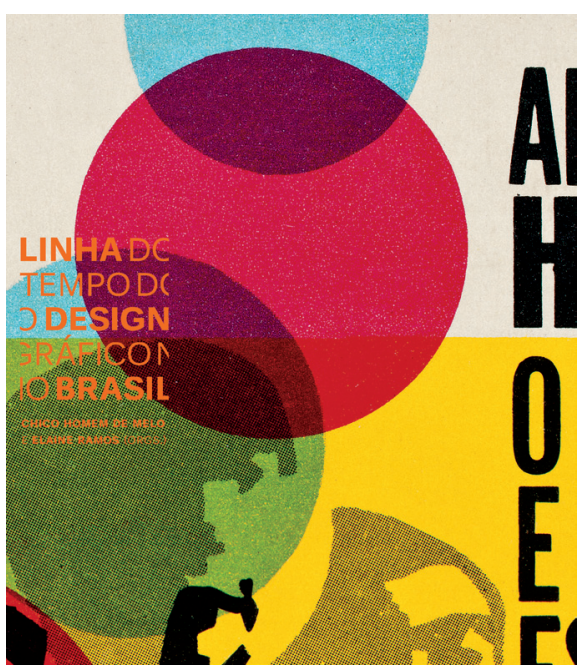

HOMEM DE MELO, C.; RAMOS, E. , A. Linha do tempo do design gráfico no Brasil.

São Paulo: Cosac Naify, 2012.

do século XXI. Dividiram-na em capítulos correspondentes a décadas - com exceção do primeiro (todo o século XIX) e segundo (1901-1919) - para criar uma obra que se lê página a página, plano a plano, década a década ou de uma vez só. Longe de serem estanques ou de terem uma tese a defender, essas divisões são, até pelo seu "evidente caráter arbitrário", menos fronteiras num mapa do que marcos num caminho. Uma ideia reforçada pela dobra de um canto da página esquerda do plano laranja fluorescente que introduz cada capítulo.

Como necessários e desejáveis filtros para um vastíssimo universo disciplinar composto por um número infindável de objetos e de tipologias foram criadas oito categorias. Aos livros, revistas e jornais - categorias "clássicas" do design 
editorial - os autores somaram sinais, cartazes e discos, e também os selos postais e cédulas.

O primeiro de mais de 1.500 marcos dessa linha do tempo mostra um documento impresso por Antonio Isidoro da Fonseca no Rio de Janeiro em 1747, muito antes de lá chegarem os prelos ingleses trazidos pela corte de D. João VI em 1808 - ano em que é criada a Impressão Régia e começa a história da impressão tipográfica no Brasil. Até então qualquer manufatura, incluindo a impressão, era proibida pela Coroa, o que leva a pensar na misteriosa origem dessa peça, bem como na imperdoável forma como um reino pôde negar, durante séculos, a chegada do progresso à sua principal colônia.

Antes de chegar ao século XX, descobrimos os Olhos de Boi, uns dos primeiros selos postais do mundo, e paramos, emocionados, não tanto na gloriosa bandeira de uma nova nação onde o Amor positivista ficou de fora "por concisão textual", mas na extraordinária primeira página do jornal A Província de São Paulo de 16 de novembro de 1889, composta apenas por um barrete frígio e as palavras "VIVA A REPUBLICA". Logo nesse capítulo é notório o desafio da eleição pelos autores de peças gráficas de exemplo e exceção, mas também o tenso mas necessário equilíbrio entre exemplos de erudição e apelo popular, vanguarda e sucesso comercial que façam justiça à história dessa arte aplicada.

Já no século passado, a modernidade entranha-se nas declinações locais de maneirismos globais como o art nouveau ou art déco para revelar a tremenda influência da Semana de Arte Moderna de 1922 tanto na época como nas futuras gerações de artistas e designers, brasilei- ros e antropófagos. O tempo acelera-se nos arranha-céus do cartaz da campanha de Júlio Prestes (1929), nas fotomontagens construtivistas e cinematográficas da breve revista S. Paulo (1936) ou nos sachplakate para bondes (1940) de Henrique Mirgalowsky, ou Mirga, um dos muitos artistas gráficos que atravessam o Atlântico antes e depois da Segunda Guerra Mundial. Entre as delirantes capas de Augustus para as reedições dos livros de Monteiro Lobato (desde 1948), as revistas de linguagem ora ousada, ora "pasteurizada" ou os rarefeitos livros da Sociedade dos Cem Bibliófilos do Brasil, chegamos aos anos 1950, dos "Cinquenta anos em cinco", mas também do "Plano piloto da poesia concreta" e da TV Tupi. O Brasil gráfico nunca mais será o mesmo depois da televisão, do retângulo do cartaz da $\mathrm{l}^{\mathrm{a}}$ Bienal de São Paulo de Antonio Maluf, dos cartazes para a Panair do Brasil de Mary Vieira ou dos Poemas, mas também do Suplemento Dominical do Jornal do Brasil de Amílcar Castro.

Tanto nas introduções aos capítulos como nas legendas expandidas das peças, os autores oferecem-nos, numa escrita viva e evocativa, exclamações, críticas, sugestões e comentários, como o que refere a polêmica trajetória do designer Aloísio Magalhães. A sua criticável ambiguidade ideológica e colaboração com o regime ufanista - manifesto em ícones como a "bicicleta de Pelé" para a Copa do Mundo de 1970, ou nas cédulas "Evolução da Raça Brasileira” de 1972 e "Barão" de 1978 - é porém minimizada pelo seu talento, legado e "defesa apaixonada da memória nacional".

A categoria dos discos começa no capítulo 1940-1949 com apenas duas capas, mas cresce exponencialmente nas 


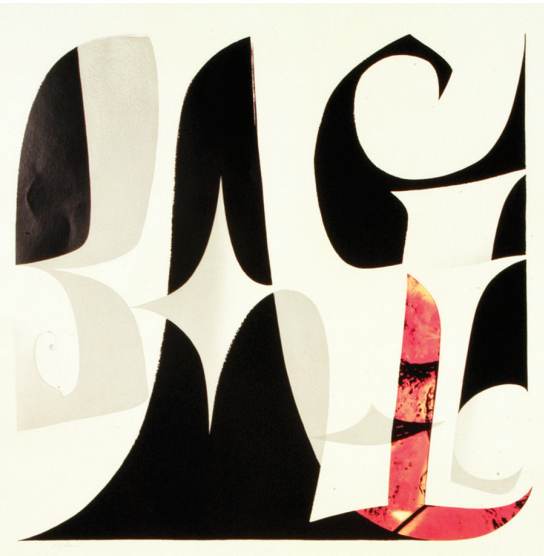

$\frac{1}{3} \frac{2}{3} \frac{3}{3}-\frac{4}{18} \frac{5}{19} \cdot \frac{6}{20} \frac{7}{21} \frac{8}{22} 9 \frac{9}{23} \frac{10}{24} \frac{11}{25} \frac{12}{26} \frac{13}{27} \frac{14}{28} \frac{15}{29} \frac{16}{30} \frac{17}{31}$

$\frac{1}{\text { Agosto }} \frac{2}{18} \frac{4}{18} \frac{5}{19} \frac{6}{20} \frac{7}{21} \frac{8}{22} \frac{9}{23} \frac{10^{\prime}}{24} \frac{11}{25} \frac{12}{26} \frac{13}{27} \frac{14}{28} \frac{15}{29} \frac{16}{30} \frac{17^{\circ}}{31}$

$\frac{12}{\text { Setembro }} 18 \frac{4}{18} \frac{5}{20} \frac{7}{21} \frac{8}{22} \frac{9^{\prime}}{23} \frac{10}{24} \frac{11}{25} \frac{12}{26} 2 \frac{14}{27} \frac{15^{\circ}}{29} \frac{16}{30}$

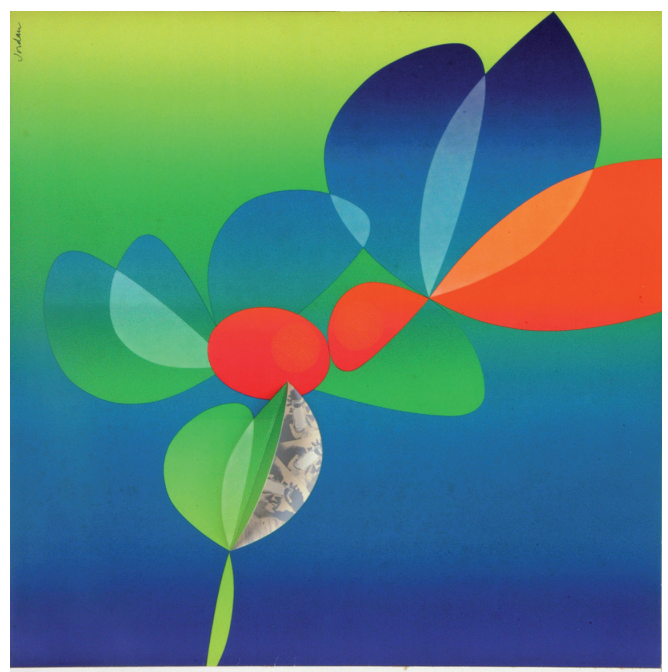

NCCOLiN
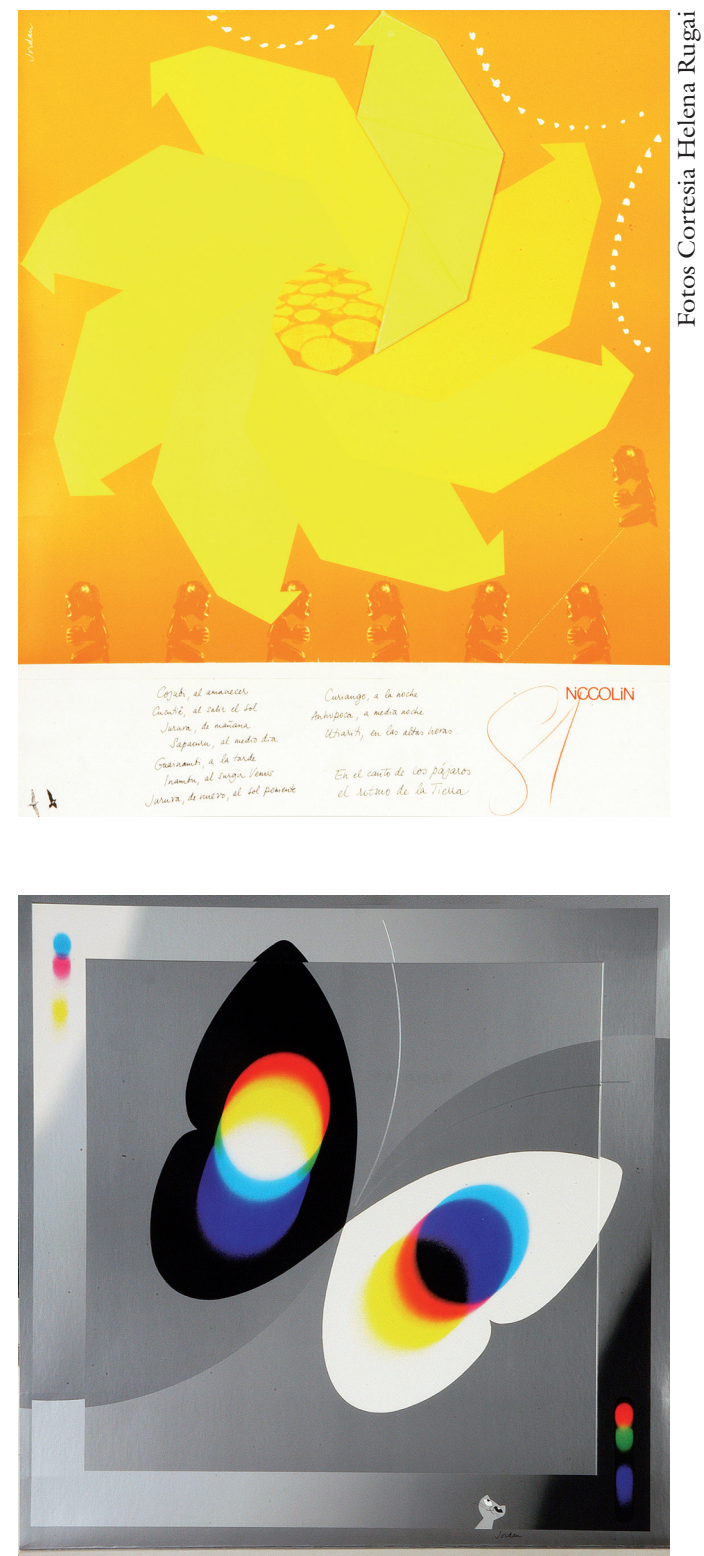

NiCCOLiN
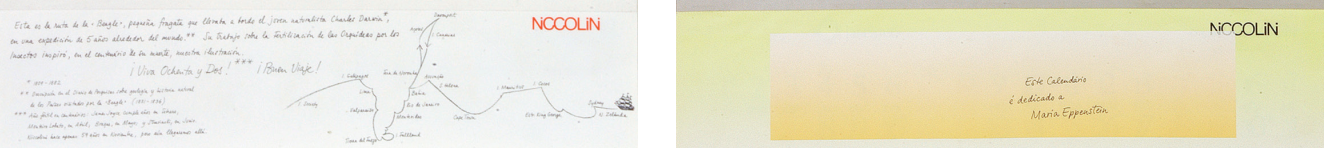

Calendários desenvolvidos pelo designer Fred Jordan (1927-2001) para a Gráfica Niccolini.

décadas seguintes. Evidencia o lugar central da música no design e visualidade do Brasil, mas também a ida e vinda de tendências e influências estéticas do modernismo e pós-modernismo, além de alguns episódios caricatos: da fotografia de João Gilberto ampliada por Cé- sar Villela em Chega de saudade (1959) à capa bauhausiana de Carlos Prósperi para O fino do fino de Elis Regina (1965), da explosão tropicalista dos anos 1960 encabeçada por Rogério Duarte (tanto nas capas de discos como nos cartazes do cinema novo) às duas capas de Re- 
gina Vater para Calabar de Chico Buarque (1973), do verdadeiro olho de Todos os olhos de Tom Zé (1973) ao "resgate" da obra de Arthur Bispo do Rosário por Gringo Cardia em Severino dos Paralamas do Sucesso (1994).

Nos anos 1960 e 1970, o funcionalismo da escola de Ulm encontra a indústria brasileira nas dezenas de sinais criados por Alexandre Wollner. Muitas das empresas, marcas e produtos a que ele deu uma face gráfica não sobreviveram porém a falências, fusões, aquisições ou tão só às ações de redesign exigidas pelo marketing nas décadas seguintes. A autoria ainda por atribuir de outras marcas e sinais, como as Havaianas ou a Varig, revela a urgência de designers e investigadores vasculharem arquivos, mas também de encontrarem e conversarem com os intervenientes ainda vivos desses projetos.

Salvo raras exceções, as imagens impressas neste livro correspondem a artefatos que resultam da múltipla replicação de um projeto. Não são reproduções de obras de arte únicas e preciosas. Não são originais. São imagens de coisas que podem ser encontradas em museus, arquivos e bibliotecas, mas também em sebos ou gavetas fechadas há muito em nossas casas. Ou ainda em leilões ou classificados na internet. Isso faz que ler esse livro nos leve a procurar, e até adquirir, os seus conteúdos. Foi precisamente isso que fiz quando procurei na internet uma das minhas imagens favoritas do livro: o cartaz do filme Brasil Verdade. Encontrei-o à venda - ou melhor, uma reprodução do projeto de Fernando Lemos de 1968, cujo estado vivido e carimbo da censura mostraram ser da época - no site mercadolivre.com. Por R\$ 40 reais. Comprei-o de imediato.
A minha compra impulsiva leva-me a refletir sobre a natureza desse livro e sobre o tempo em que é publicado. Seu formato, tamanho, peso e preço (quase R\$ 200 reais) destinam-no a tornar-se um "livro de mesa de centro". Esse não merece tal destino, merece antes ser lido, partilhado, discutido e acarinhado por designers brasileiros - e outros falantes da língua portuguesa. Mas será um grande, pesado e caro livro a melhor forma de levar essas palavras e imagens a estudantes, profissionais e demais interessados na sua história? Entre uma exposição realizada a partir de uma difícil e custosa seleção de artefatos “originais", um mais acessível conjunto de fascículos associado a uma publicação periódica, ou um ficheiro digital iluminado sem custos num ecrã perante os nossos olhos, será um livro apenas mais um, mas não necessariamente mais apropriado, de vários meios possíveis para cumprir esse destino?

Chico Homem de Melo remata a introdução ao capítulo dos anos 1960 com os versos de Caetano e Gil "Atenção, tudo é perigoso / Tudo é divino, maravilhoso", que para ele traduzem "o paradoxo vivido naquele período tão arrebatador". Os tempos em que vivemos são para obras como essa igualmente arrebatadores e paradoxais. O projeto pode ser maravilhoso, mas atenção: o livro está em perigo.

Frederico Duarte estudou Design de Comunicação em Lisboa e crítica de design em Nova York. Como crítico e curador de design, escreve, comissaria e organiza iniciativas sobre design, arquitetura e criatividade. Atualmente leciona na ESAD Caldas da Rainha e na Faculdade de Belas Artes da Universidade de Lisboa. @ - frederico@05031979.net 